\title{
Study of Thermal Stability of Ni Silicide using Ni-V Alloy
}

\author{
Zhun Zhong, Soon-Young Oh, Won-Jae Lee, Ying-Ying Zhang, Soon-Yen Jung, \\ Shi-Guang Li, Ga-Won Lee, Jin-Suk Wang, and Hi-Deok Lee ${ }^{\mathrm{a}}$ \\ Department of Electrical Engineering, Chungnam National University, \\ 220 Gung-dong, YuSeung-gu, Daejeon 305-764, Korea \\ Yeong-Cheol Kim \\ Department of Materials Engineering, Korea University of Technology and Education, \\ Gajeonri 307, Byeongcheon-myeon, Cheonan-si, Chungnam 330-702, Korea \\ aE-mail : $\underline{\text { hdlee@gcnu.ac.kr }}$
}

(Received September 6 2006, Accepted February 18 2008)

\begin{abstract}
In this paper, thermal stability of Nickel silicide formed on p-type silicon wafer using Ni-V alloy film was studied. As compared with pure Ni, Ni-V shows better thermal stability. The addition of Vanadium suppresses the phase transition of $\mathrm{NiSi}_{\text {to }} \mathrm{NiSi}_{2}$ effectively. $\mathrm{Ni}-\mathrm{V}$ single structure shows the best thermal stability compared with the other Ni-silicide using TiN and $\mathrm{Co} / \mathrm{TiN}$ capping layers. To enhance the thermal stability up to $650{ }^{\circ} \mathrm{C}$ and find out the optimal thickness of Ni silicide, different thickness of $\mathrm{Ni}-\mathrm{V}$ was also investigated in this work.
\end{abstract}

Keywords : Ni-V(Nickel vanadium) alloy, Thermal stability, Ni silicide, RTP

\section{INTRODUCTION}

The Self-aligned silicide (Salicide) is one of the key methods in modern ULSI technologies to increase device speed by reducing the series resistance of source/drain and gate[1-3]. Titanium silicide $\left(\mathrm{TiSi}_{2}\right)$ was firstly used in the 0.35 -um complementary metal oxide semiconductor (CMOS) technology attribute to its low sheet resistance and high thermal immunity. However, due to the difficulty of the phase transition from $\mathrm{C}_{49}$ to $\mathrm{C}_{54}$ on a very narrow line, which can induce a dramatic increase in the sheet resistance, $\mathrm{TiSi}_{2}$ was replaced by $\mathrm{CoSi}_{2}$ in 0.25 -um CMOS technology. However, the $\mathrm{CoSi}_{2}$ also has its drawbacks, such as the high consumption of the silicon and large increment of the sheet resistance below sub-100 nm MOSFETs. Therefore, nowadays, nickel silicide (NiSi) is being rese arched actively as a substitute of $\mathrm{TiSi}_{2}$ and $\mathrm{CoSi}_{2}$ in nanoscale CMOS device fabrication processes. Ni silicide (NiSi) has characteristics like low resistivity, low formation temperature, small stress and less silicon consumption compared with the commonly used $\mathrm{TiSi}_{2}$ and $\mathrm{CoSi}_{2}$ [4-6]. All of these features made NiSi as a competent material for nanoscale CMOSFETs. In addi tion, the low-resistivity Nickel monosilicide ( $\mathrm{NiSi}$ ) can be easily obtained from one step rapid thermal process (RTP) at low temperature. However, the thermal stability of Ni silicide is poor because of the formation of highresistivity phase $\mathrm{NiSi}_{2}$, which is the main obstacle to the successful application of NiSi in conventional ULSI processes. In order to improve its thermal stability, many approaches such as ion implantation[7], alloy target of $\mathrm{NiTa}[8]$, NiPt [9] and deposition of inter- and/or capping- layers have been proposed[10].

In this paper, various film structures such as $\mathrm{Ni}-\mathrm{V}$, Ni$\mathrm{V} / \mathrm{TiN}$ and $\mathrm{Ni}-\mathrm{V} / \mathrm{Co} / \mathrm{TiN}$ had been investigated to enhance the thermal stability of Ni silicide. It is proved that $\mathrm{Ni}-\mathrm{V}$ has a better thermal stable characteristic $\mathrm{w}$ hen compared with $\mathrm{Ni}-\mathrm{V} / \mathrm{TiN}$ and $\mathrm{Ni}-\mathrm{V} / \mathrm{Co} / \mathrm{TiN}$. Moreover, as the thickness of Ni-V structure increased, the sheet resistance was shown to be more stable. As a result, $\mathrm{NiSi}$ utilizing $\mathrm{Ni}-\mathrm{V}$ alloy is most recommended for highly thermal immune CMOS technology.

\section{EXPERIMENT}

In this experiment, four structures of $\mathrm{Ni}(8 \mathrm{~nm}), \mathrm{Ni}-\mathrm{V}$ $(8 \mathrm{~nm}), \mathrm{Ni}-\mathrm{V} / \mathrm{TiN}(8 / 25 \mathrm{~nm})$, and $\mathrm{Ni}-\mathrm{V} / \mathrm{Co} / \mathrm{TiN}(6 / 2 / 25$ $\mathrm{nm})$ were deposited on p-type $\mathrm{Si}$ wafers using $\mathrm{RF}$ magnetron sputtering system without breaking vacuum after removal of the native oxide in the $\mathrm{HF}$ dilute solution $\left(\mathrm{HF}: \mathrm{H}_{2} \mathrm{O}=1: 100\right)$. Nickel silicide was formed in rapid thermal process (RTP) at various temperatures $\left(400,500,600,650\right.$ and $\left.700{ }^{\circ} \mathrm{C}\right)$ for $30 \mathrm{sec}$. Un-reacted metals were selectively wet-etched in $\mathrm{H}_{2} \mathrm{SO}_{4}$ $+\mathrm{H}_{2} \mathrm{O}_{2}(4: 1)$ solution. To test the thermal stability of nickel silicide, post-silicidation annealing was carried 
out at three different temperatures $\left(550,600\right.$ and $\left.650{ }^{\circ} \mathrm{C}\right)$ for $30 \mathrm{~min}$ with $\mathrm{N}_{2}$ ambient. Sheet resistance of nickel silicide was measured using conventional four point probe (FPP). AFM (Atomic Force Microscope) and XRD (X-ray Diffraction) analysis were performed to investigate surface roughness and phase identification. Thickness and morphologies of Nickel silicide were characterized by FE-SEM (Field Emission Scanning Electron Microscopy, Jeon-ju Branch of the Korea Basic Science Institute, Model S-4700).

\section{RESULTS AND DISCUSSION}

Phase transition study shows the influence of vanadium addition on stability of nickel silicide. Phase transition curves of $\mathrm{Ni}$ and $\mathrm{Ni}-\mathrm{V}$ films on p-type silicon were obtained as in Fig. $1 . \mathrm{Ni}-\mathrm{V}$ case shows lower sheet resistance and wider RTP window compared with $\mathrm{Ni}$ only case. Moreover, there is a drastic improvement of thermal stability by addition of Vanadium as shown in Fig. 1(b). After post-silicidation annealing, Ni-V silicide film remains more stable than the pure $\mathrm{Ni}$ film of the same physical thickness. These results imply that the addition of vanadium makes $\mathrm{NiSi}$ more stable and enlarges the RTP process window by suppressing the phase transition to high resistive $\mathrm{NiSi}_{2}$.

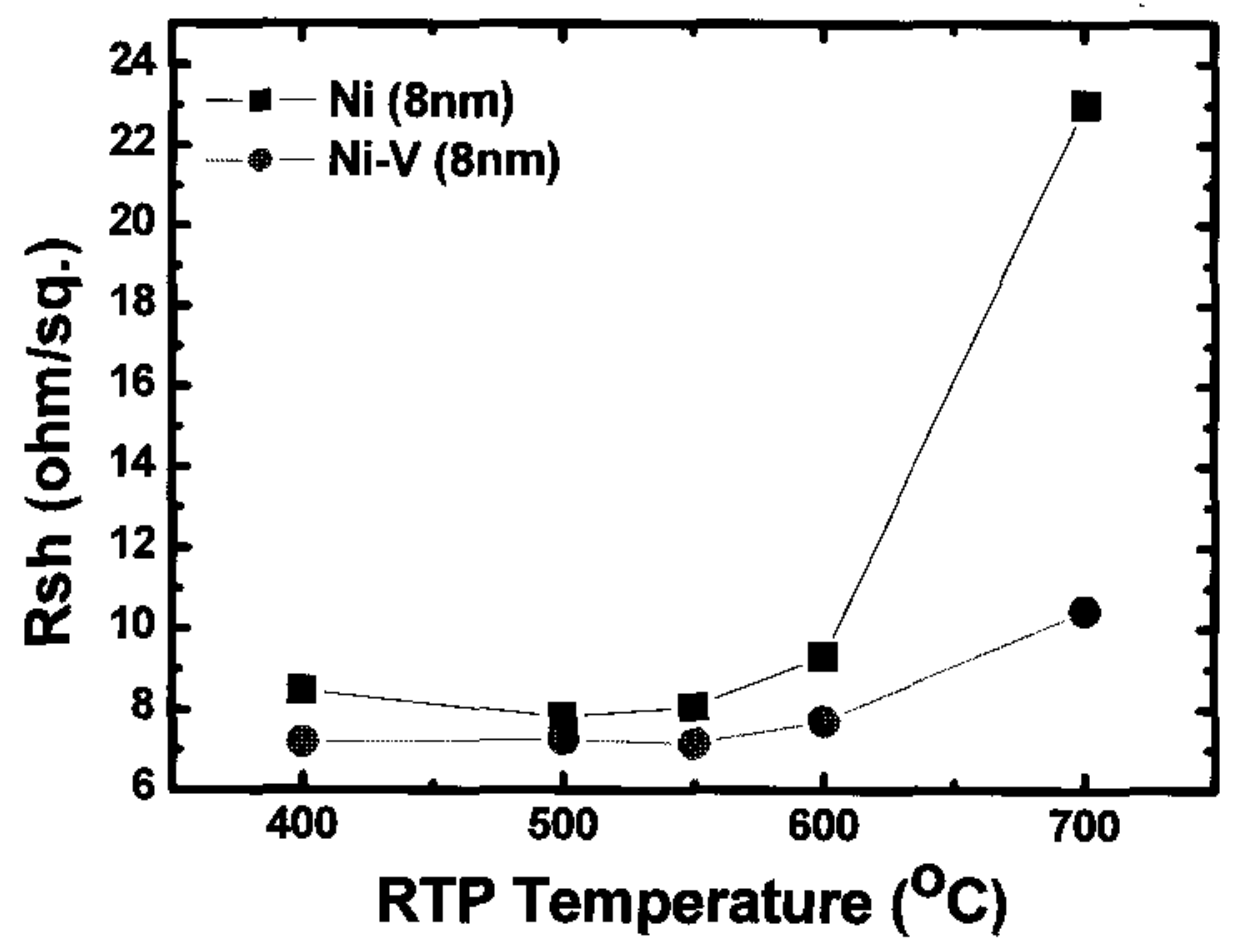

(a)

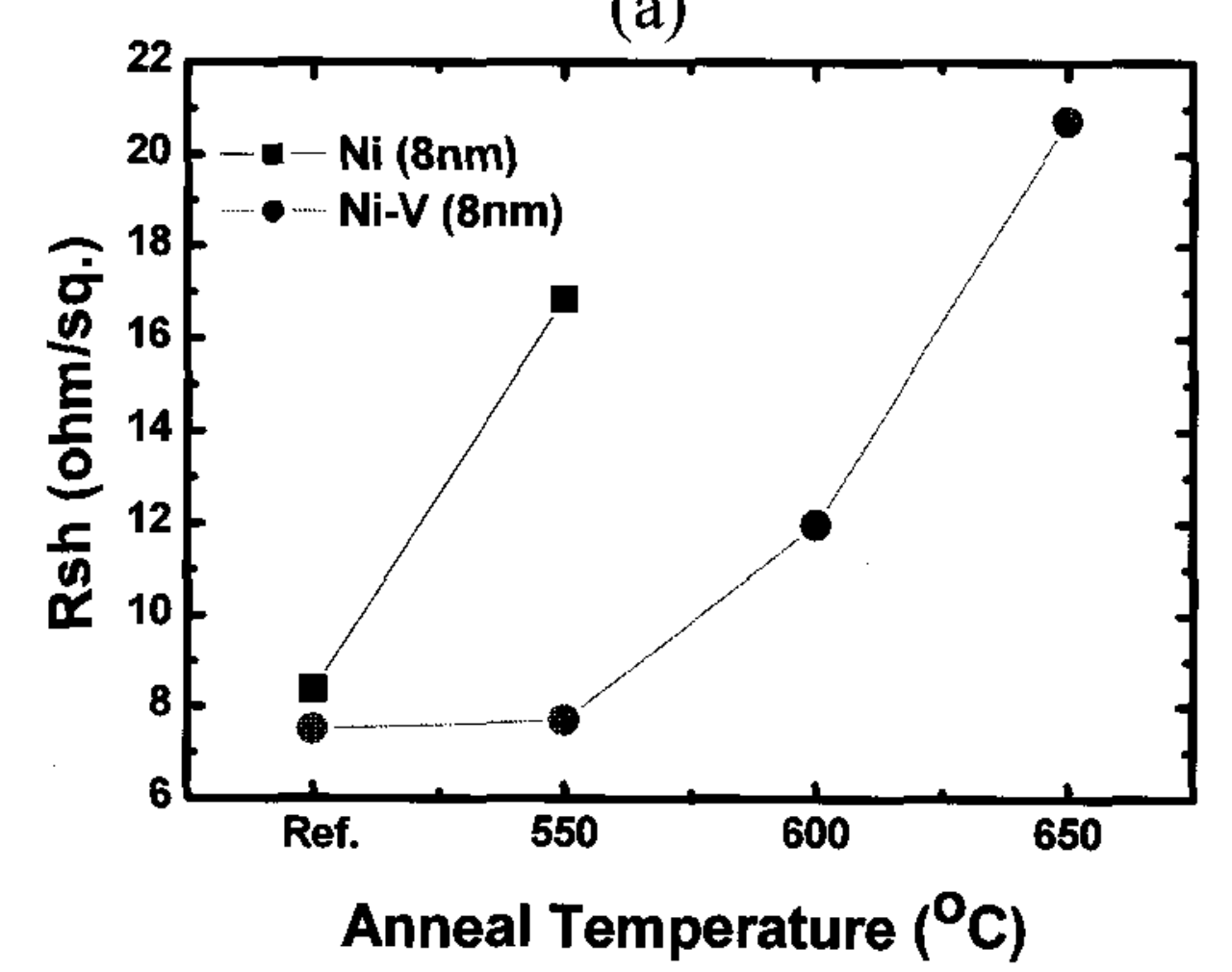

(b)

Fig. 1. Sheet resistance as a function of RTP temperature (a) and post-silicidation annealing (b) for $\mathrm{Ni}-\mathrm{V}$ alloy and pure Ni cases.

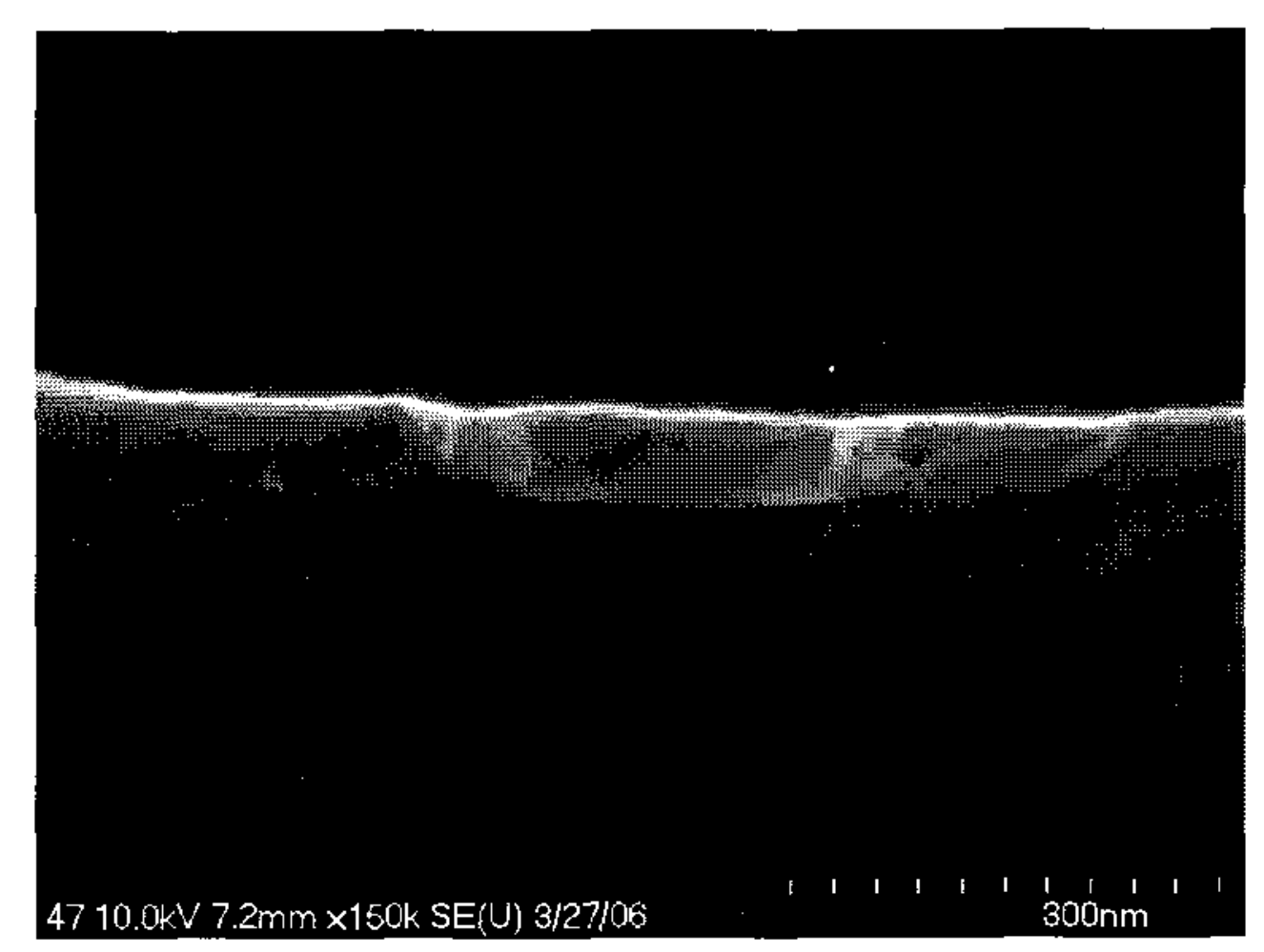

(a) $\mathrm{Ni}$

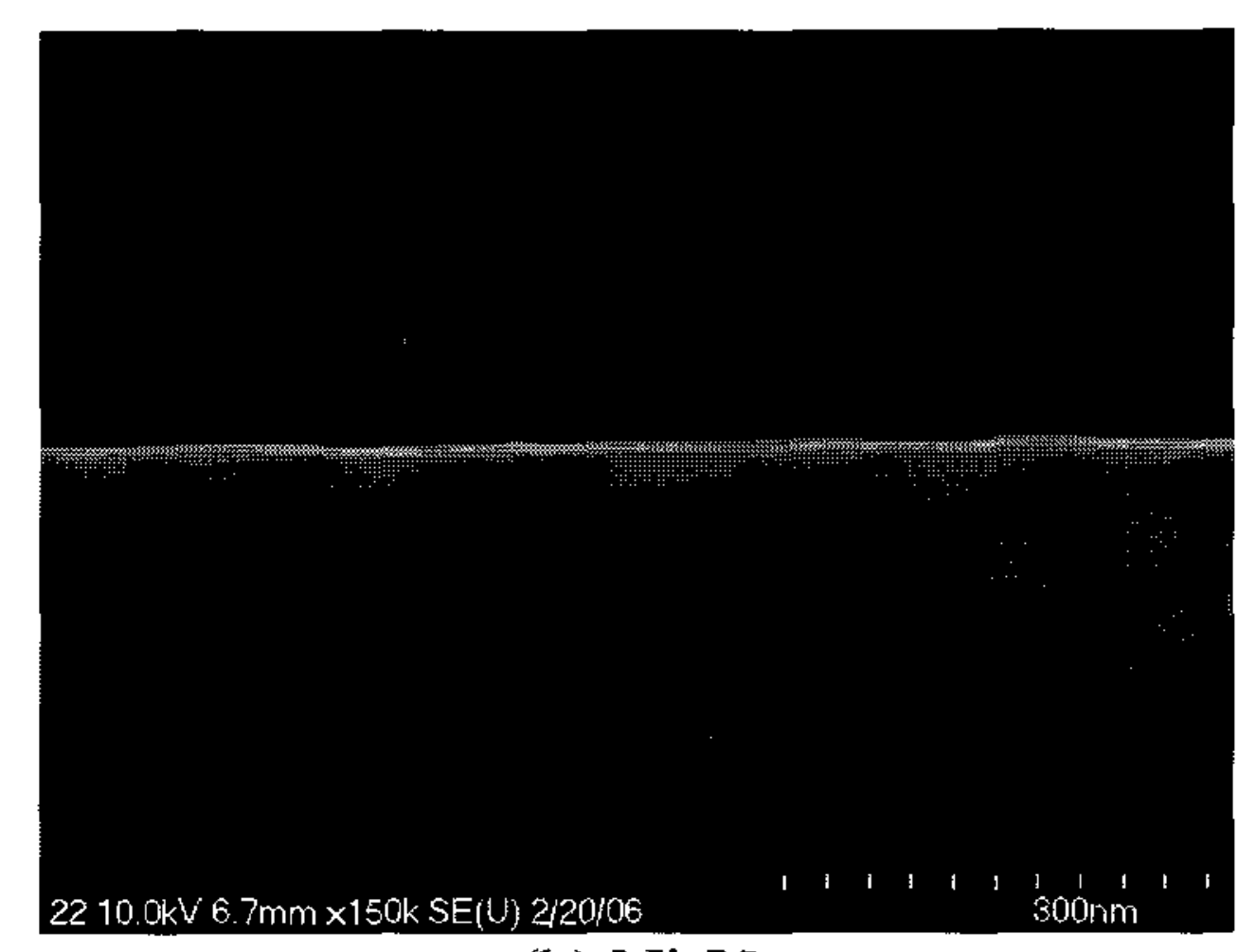

(b) Ni-V

Fig. 2. FESEM images of NiSi for pure $\mathrm{Ni}$ (a) and $\mathrm{Ni}$ $\mathrm{V}$ alloy (b) after post-silicidation annealing at $600^{\circ} \mathrm{C}$.

FE-SEM images of nickel silicide for pure $\mathrm{Ni}$ and $\mathrm{Ni}-\mathrm{V}$ alloy were shown in Fig. 2. In case of pure $\mathrm{Ni}$ structure, NiSi was agglomerated and large silicide island was found. However, $\mathrm{NiSi}$ with $\mathrm{Ni}-\mathrm{V}$ case maintained stable resistance even after the postsilicidation annealing for $30 \mathrm{~min}$ at $600{ }^{\circ} \mathrm{C}$ and the result is well matched with sheet resistance properties as shown in Fig. 1(b).

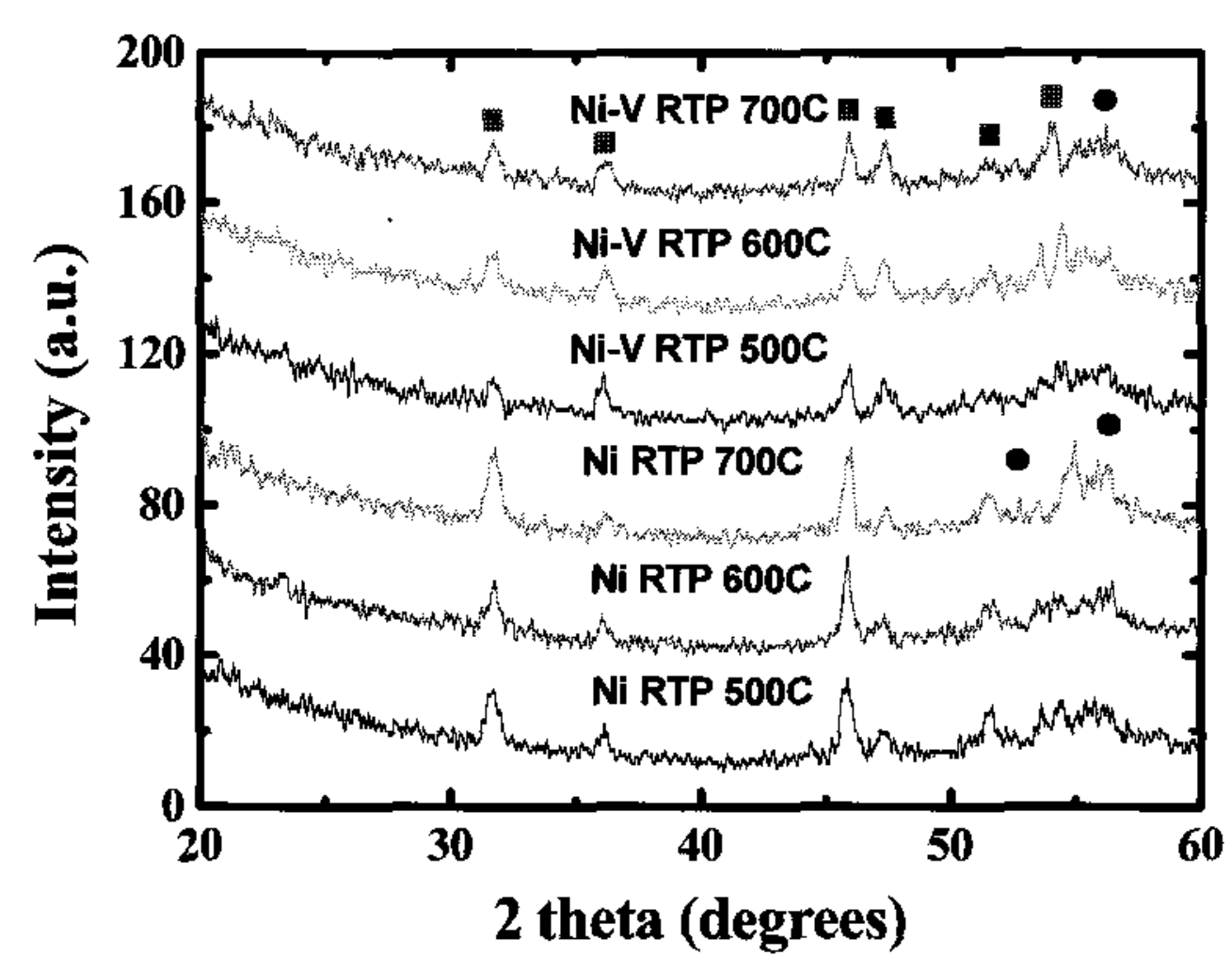

Fig. 3. XRD scans of pure-Ni and $\mathrm{Ni}-\mathrm{V}$ silicide for both RTP temperatures of $500-700{ }^{\circ} \mathrm{C}($ for NiSi and $\bullet$ for $\mathrm{NiSi}_{2}$ ). 
XRD was used to identify the silicide phases as presented in Fig. 3. Almost same profiles were obtained from pure-Ni and $\mathrm{Ni}-\mathrm{V}$ cases. However, in case of $\mathrm{Ni}-\mathrm{V}$, less $\mathrm{NiSi}_{2}$ peaks were observed reflecting that better thermal stability than pure-Ni structure. The result suggests that the addition of vanadium suppresses the phase transition of $\mathrm{NiSi}$ to high resistive $\mathrm{NiSi}_{2}$ effectively.

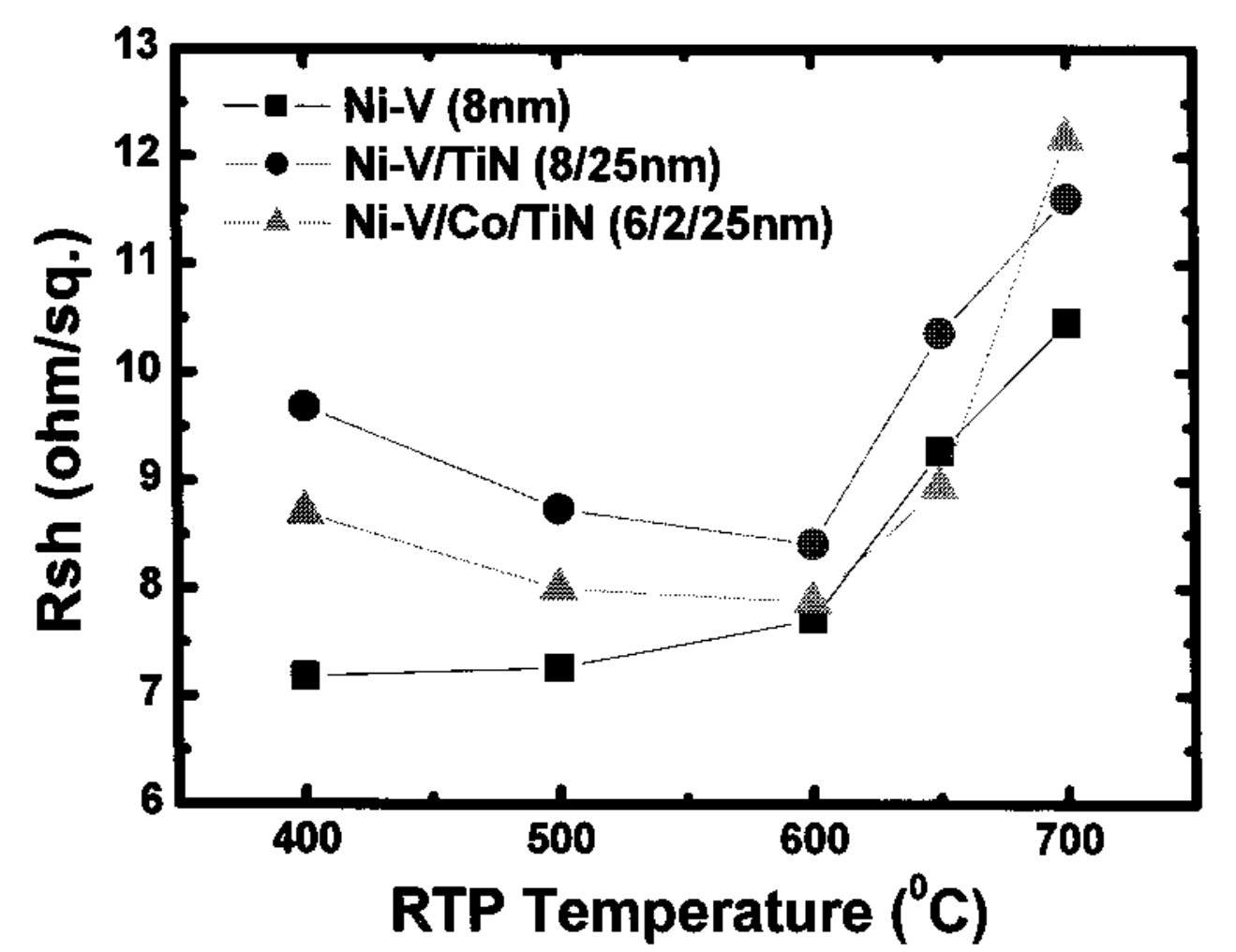

(a)

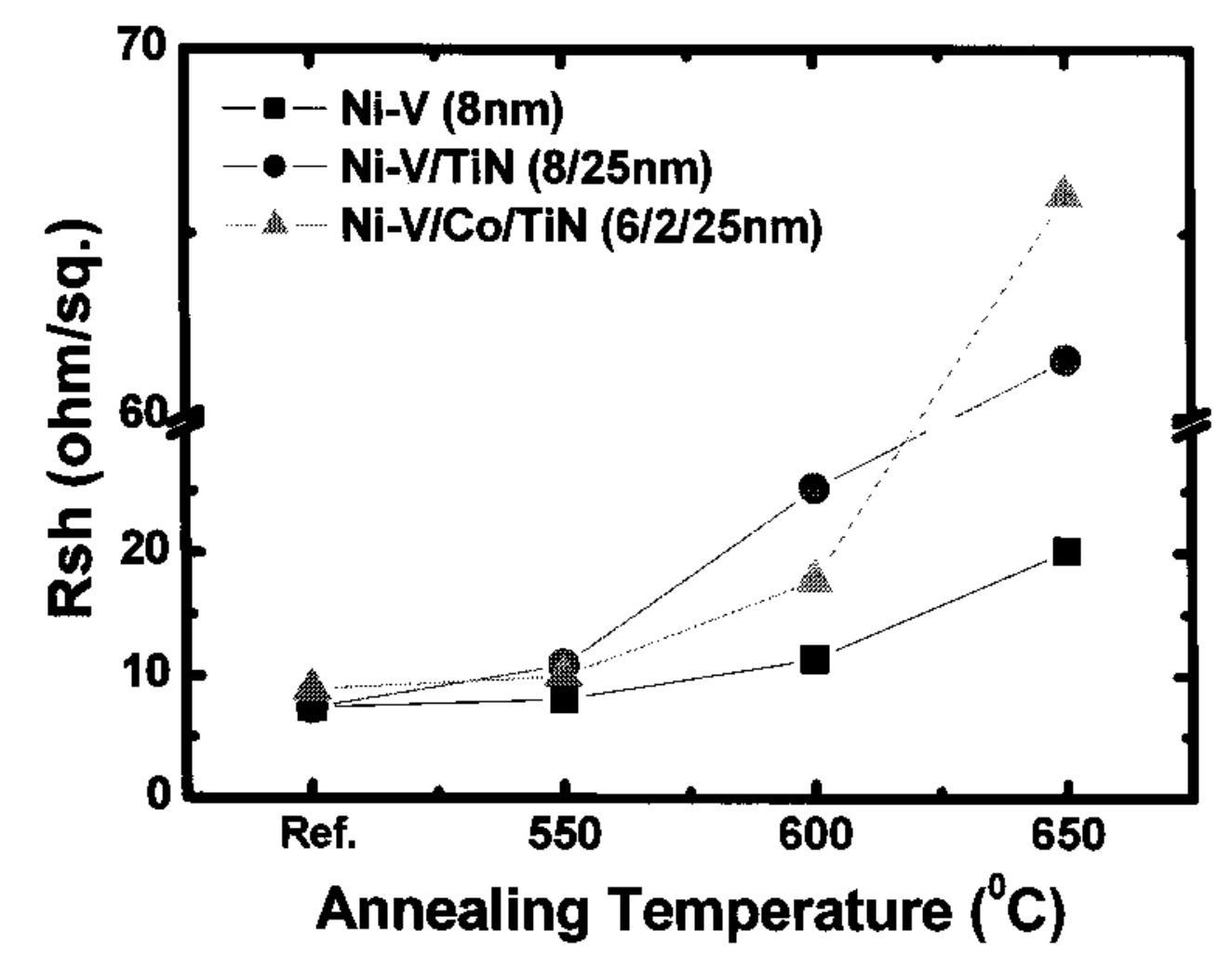

(b)

Fig. 4. Sheet resistance of Nickel silicide after (a) RTP and (b) post-silicidation annealing.

Figure 4(a) shows the sheet resistance of nickel silicide after different RTP temperatures. It can be seen that $\mathrm{Ni}-\mathrm{V}$ structure has lower sheet resistance compared with other structures. Moreover, after post-silicidation annealing for $30 \mathrm{~min}$, nickel silicide formed with $\mathrm{Ni}-\mathrm{V}$ system shows better thermal stability than that formed with $\mathrm{Ni}-\mathrm{V} / \mathrm{TiN}$ and $\mathrm{Ni}-\mathrm{V} / \mathrm{Co} / \mathrm{TiN}$ structures as shown in Fig. 4(b). It is quite interesting that sheet resistance of $\mathrm{Ni}$-silicide increases by the adoption of capping layers such as $\mathrm{TiN}$ and $\mathrm{Co} / \mathrm{TiN}$. But in case of pure Ni target, sheet resistance decreased by using capping layers. Sheet resistance of nickel silicide shows drastic increase from annealing temperature at $600{ }^{\circ} \mathrm{C}$. To explain this phenomenon, the surface roughness and cross-sectional profiles were investigated.

Figure 5 shows surface roughness of silicides formed with $\mathrm{Ni}-\mathrm{V}, \mathrm{Ni}-\mathrm{V} / \mathrm{TiN}$ and $\mathrm{Ni}-\mathrm{V} / \mathrm{Co} / \mathrm{TiN}$. The picture of $\mathrm{Ni}-\mathrm{V}$ (RMS=1.6 nm) shows better surface roughness than $\mathrm{Ni}-\mathrm{V} / \mathrm{TiN}(\mathrm{RMS}=1.7 \mathrm{~nm})$ and $\mathrm{Ni}-\mathrm{V} / \mathrm{Co} / \mathrm{TiN}(\mathrm{RMS}=$ $3.5 \mathrm{~nm}$ ). The difference of surface roughness, however, is not serious.

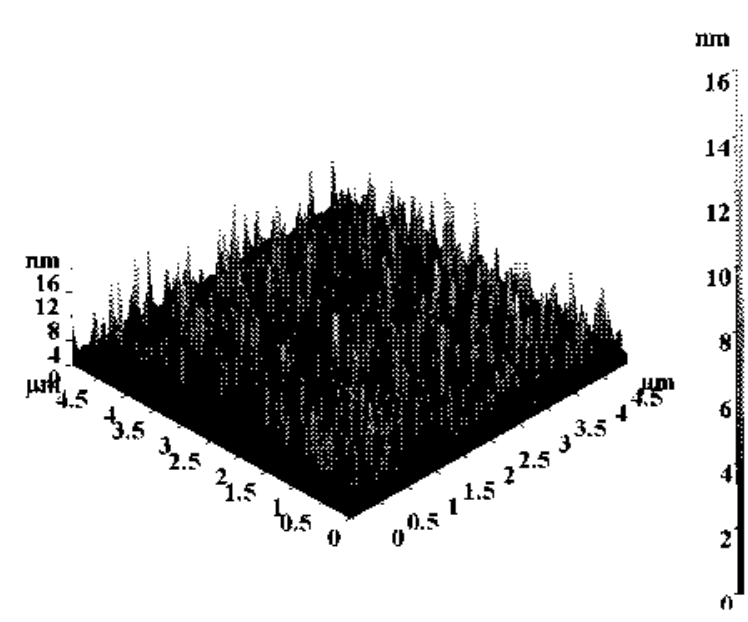

(a) Roughness $=0.9 \mathrm{~nm}$

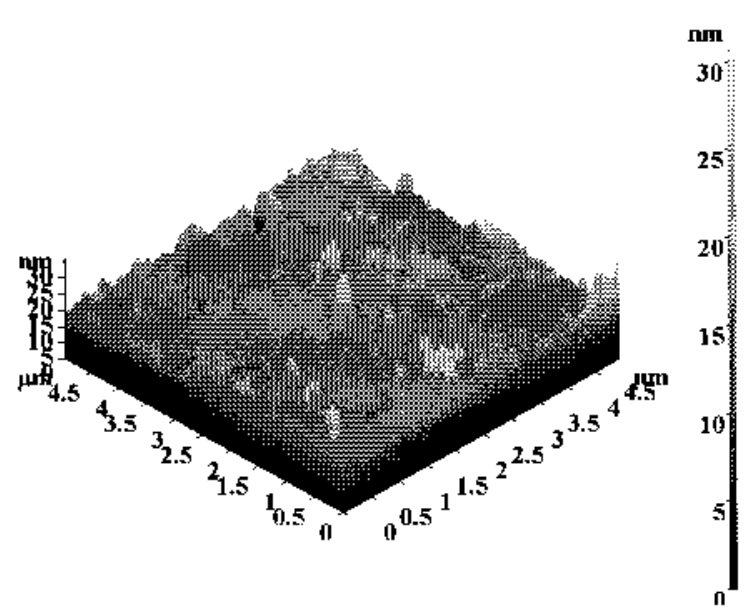

(b) Roughness $=1.6 \mathrm{~nm}$ $\mathrm{Ni}-\mathrm{V}(8 \mathrm{~nm})$

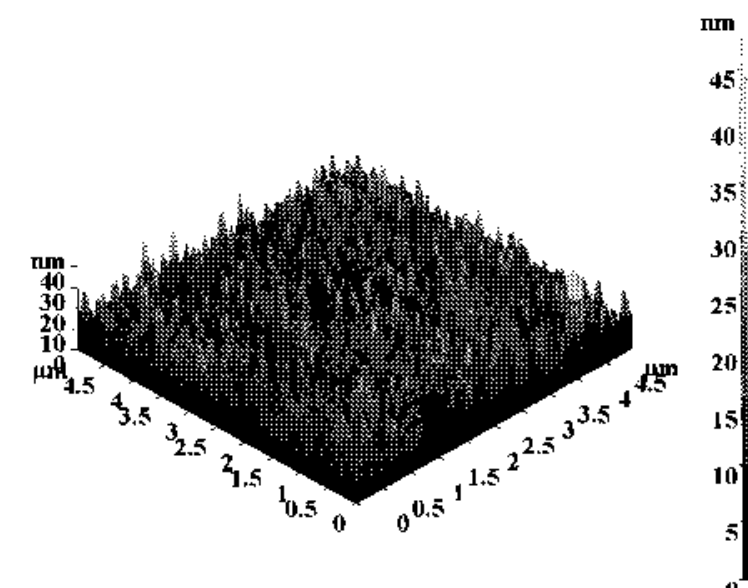

(c) Roughness $=1.3 \mathrm{~nm}$

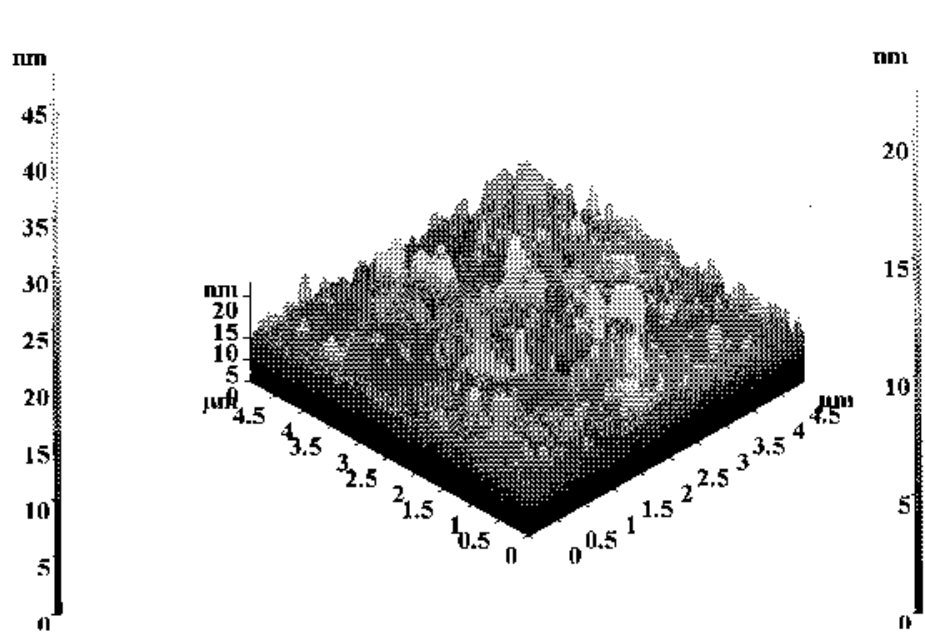

(d) Roughness $=1.7 \mathrm{~nm}$ $\mathrm{Ni}-\mathrm{V} / \mathrm{TiN}(8 / 25 \mathrm{~nm})$

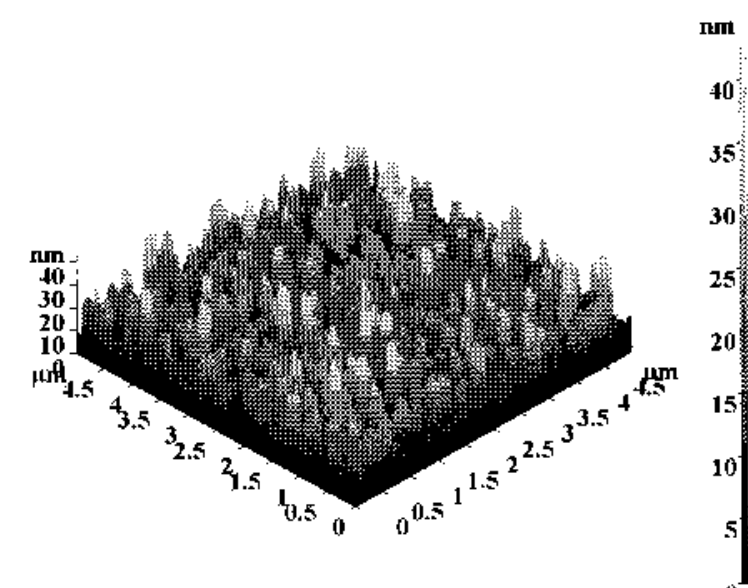

(e) Roughness $=1.6 \mathrm{~nm}$

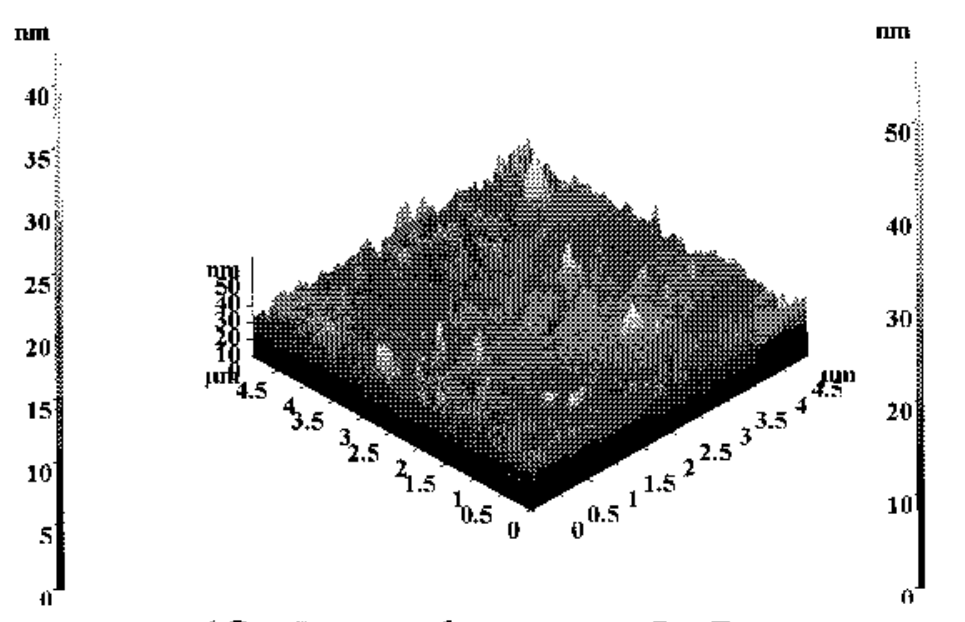

(f) Roughness $=3.5 \mathrm{~nm}$ $\mathrm{Ni}-\mathrm{V} / \mathrm{Co} / \mathrm{TiN}(8 / 2 / 25 \mathrm{~nm})$

Fig. 5. AFM surface roughness of NiSi before postsilicidation annealing (a), (c), (e) and after postsilicidation annealing (b), (d), (f).

Figure 6 are the cross-sectional FE-SEM images of nickel silicide before and after post-silicidation annealing. The interface of $\mathrm{NiSi} / \mathrm{Si}$ shows uniform and the thickness of NiSi shows similar property in all three cases. However, after post-silicidation annealing, the $\mathrm{Ni}-\mathrm{V} / \mathrm{TiN}$ and the $\mathrm{Ni}-\mathrm{V} / \mathrm{Co} / \mathrm{TiN}$ show agglomerations after post-silicidation annealing. Contrary to these cases, $\mathrm{Ni}-\mathrm{V}$ presents a better $\mathrm{NiSi} / \mathrm{Si}$ interface profile. Because the agglomeration usually accompanies the phase transition from low-resistivity phase mono-silicide 
(NiSi) to high-resistivity phase disilicide $\left(\mathrm{NiSi}_{2}\right)$, the drastic increase of sheet resistance after post-silicidation annealing temperature at $650{ }^{\circ} \mathrm{C}$ that shown in Fig. 4(b) can be explained by the agglomeration of Ni-silicide during high temperature post-silicidation annealing.

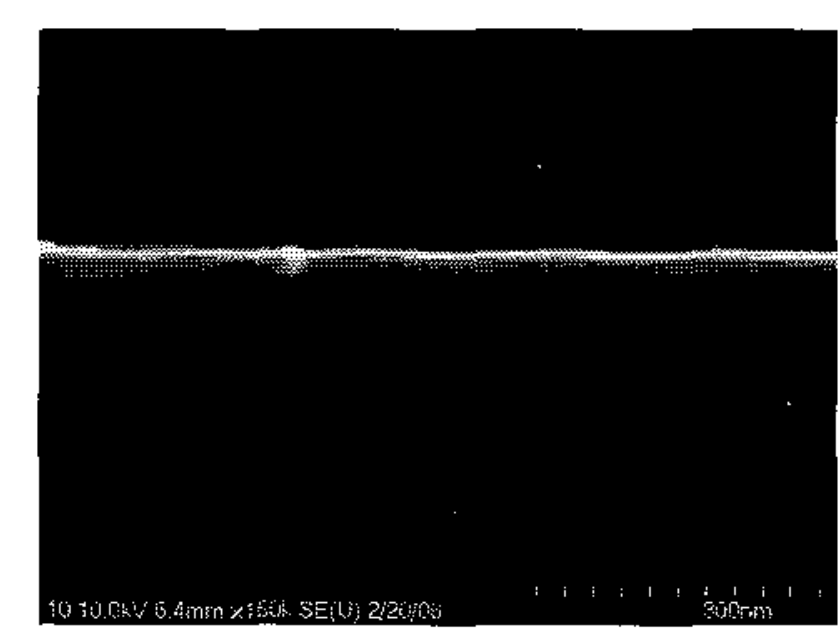

(a) $\mathrm{Ni}-\mathrm{V}$

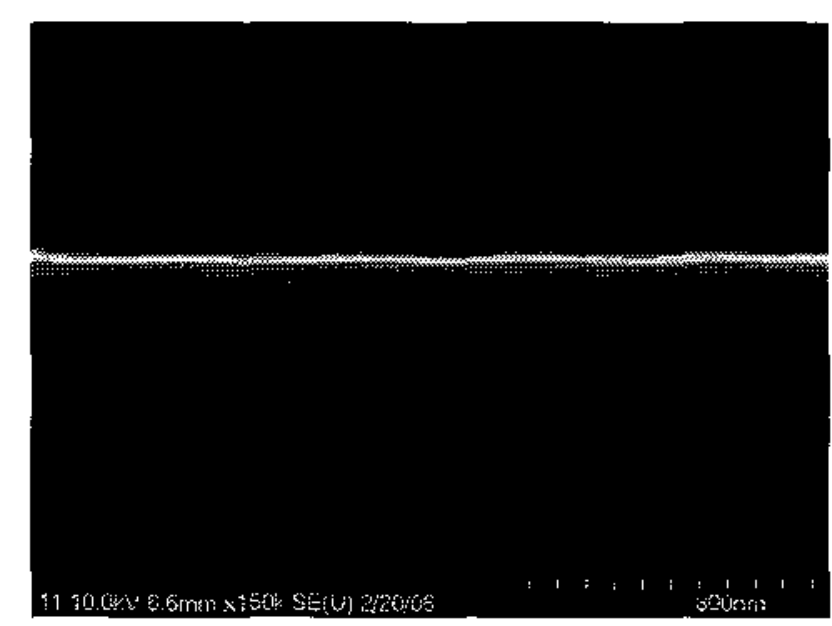

(c) $\mathrm{Ni}-\mathrm{V} / \mathrm{TiN}$

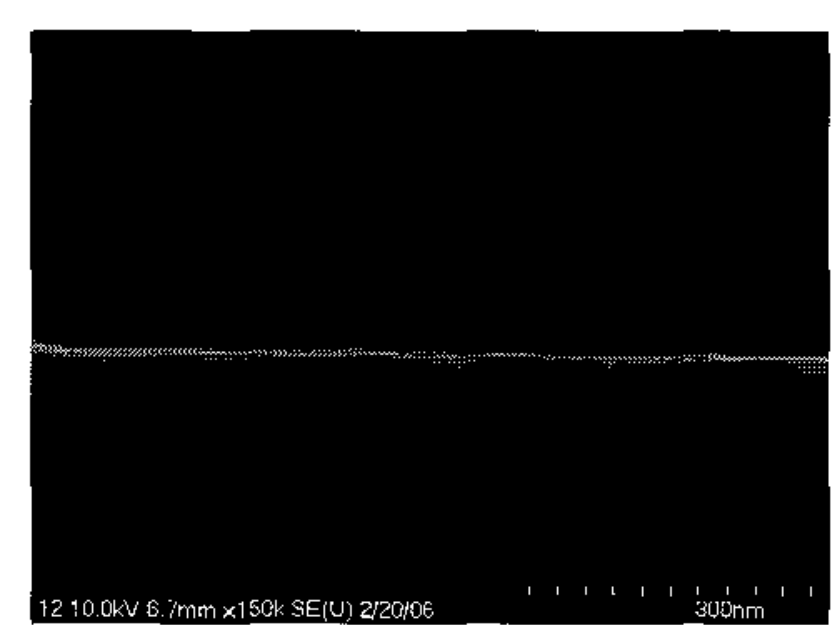

(e) $\mathrm{Ni}-\mathrm{V} / \mathrm{Co} / \mathrm{TiN}$
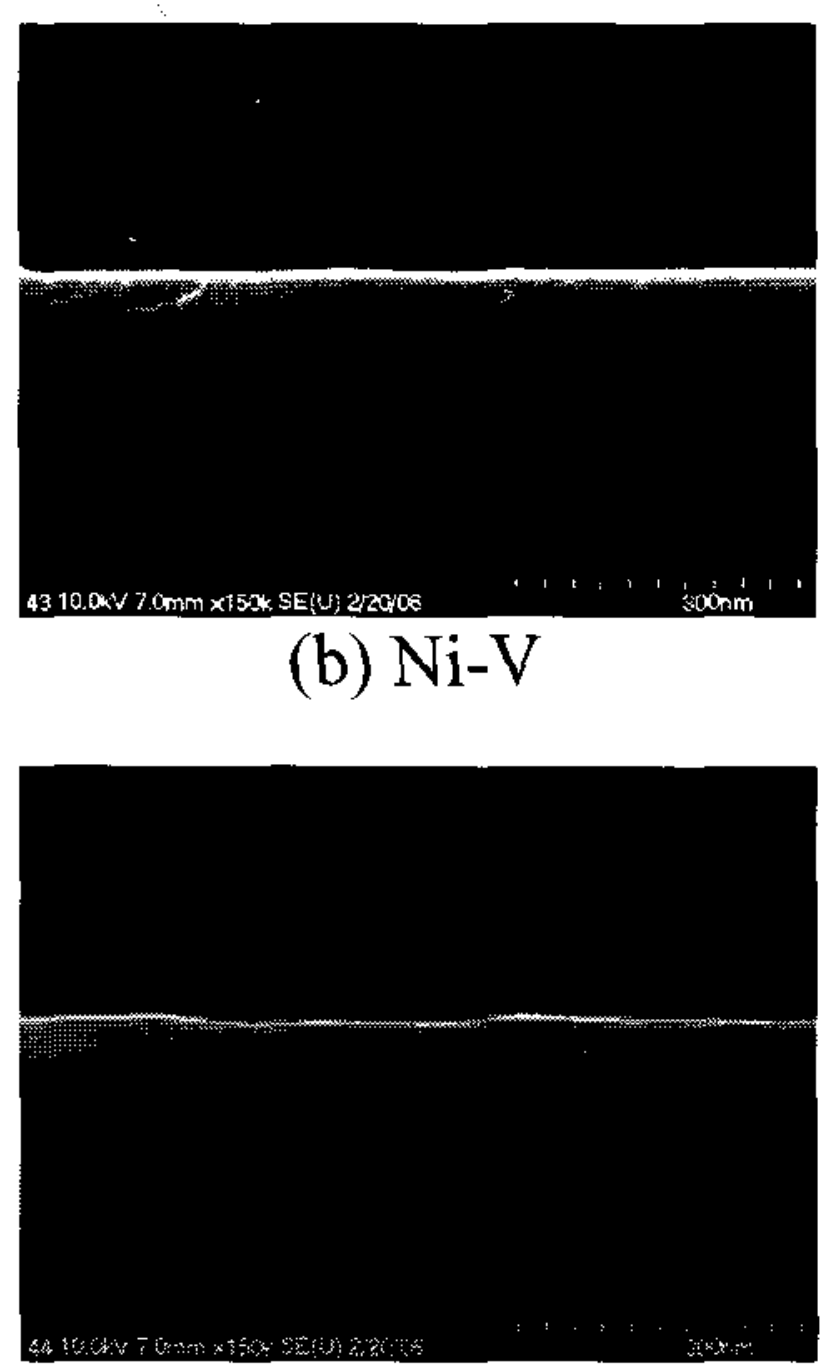

(d) $\mathrm{Ni}-\mathrm{V} / \mathrm{TiN}$

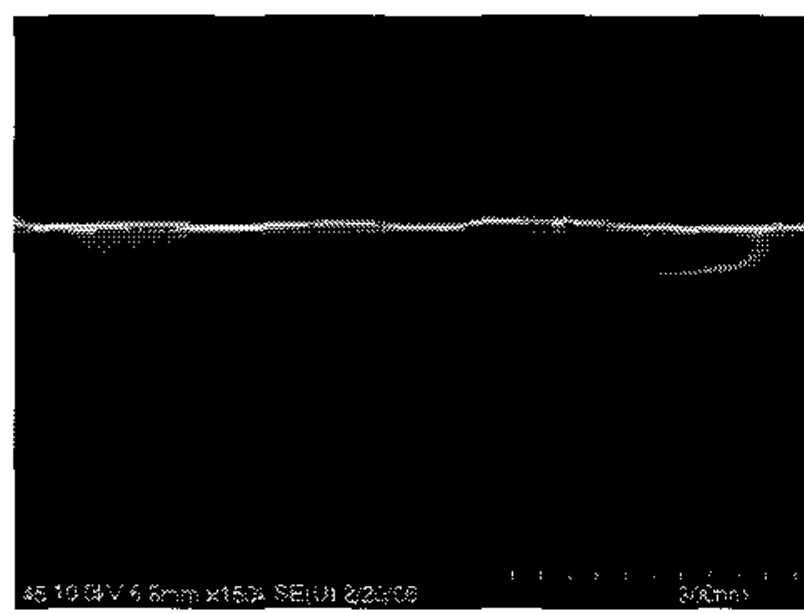

(f) $\mathrm{Ni}-\mathrm{V} / \mathrm{Co} / \mathrm{TiN}$ (b) $\mathrm{Ni}-\mathrm{V}$

Fig. 6. FE-SEM cross-sectional profile of NiSi before post-silicidation annealing (a), (c), (e) and after postsilicidation annealing (b), (d), (f).

Figure 7 indicates that the thermal stability of Nickel silicide is dependent on the thickness of Ni-V film. The sheet resistance of nickel silicide with $8 \mathrm{~nm} \mathrm{Ni-V}$ becomes more than $10 \mathrm{Ohm} / \mathrm{Sq}$ while $15 \mathrm{~nm} \mathrm{Ni-V}$ maintains its low and stable sheet resistance after postsilicidation annealing at $600{ }^{\circ} \mathrm{C}$. Therefore, film thickness should be carefully decided for nano-scale CMOS technology.

\section{CONCLUSION}

The nickel silicide properties were studied in this paper. Better thermal stability was achieved by the proposed $\mathrm{Ni}-\mathrm{V}$ structure while sheet resistance of the $\mathrm{Ni}$ $\mathrm{V} / \mathrm{TiN}$ and the $\mathrm{Ni}-\mathrm{V} / \mathrm{Co} / \mathrm{TiN}$ increases abruptly after post-silicidation annealing at $600{ }^{\circ} \mathrm{C}$. Ni-V structure also shows smoother cross-sectional profile than the other structures. Moreover, in case of Ni-V system, it is found that the sheet resistance becomes more stable as the thickness of $\mathrm{Ni}-\mathrm{V}$ structure increased.

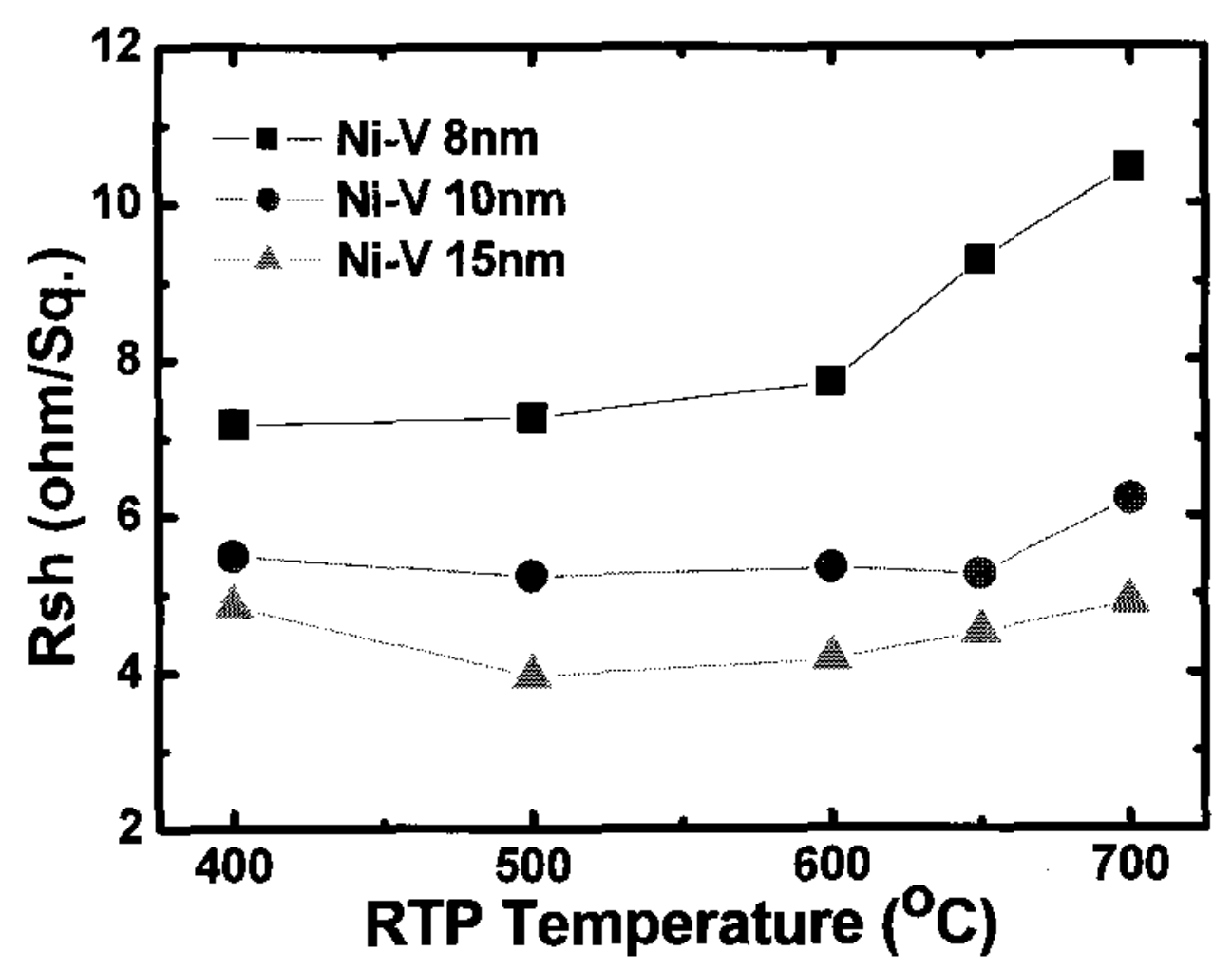

(a)

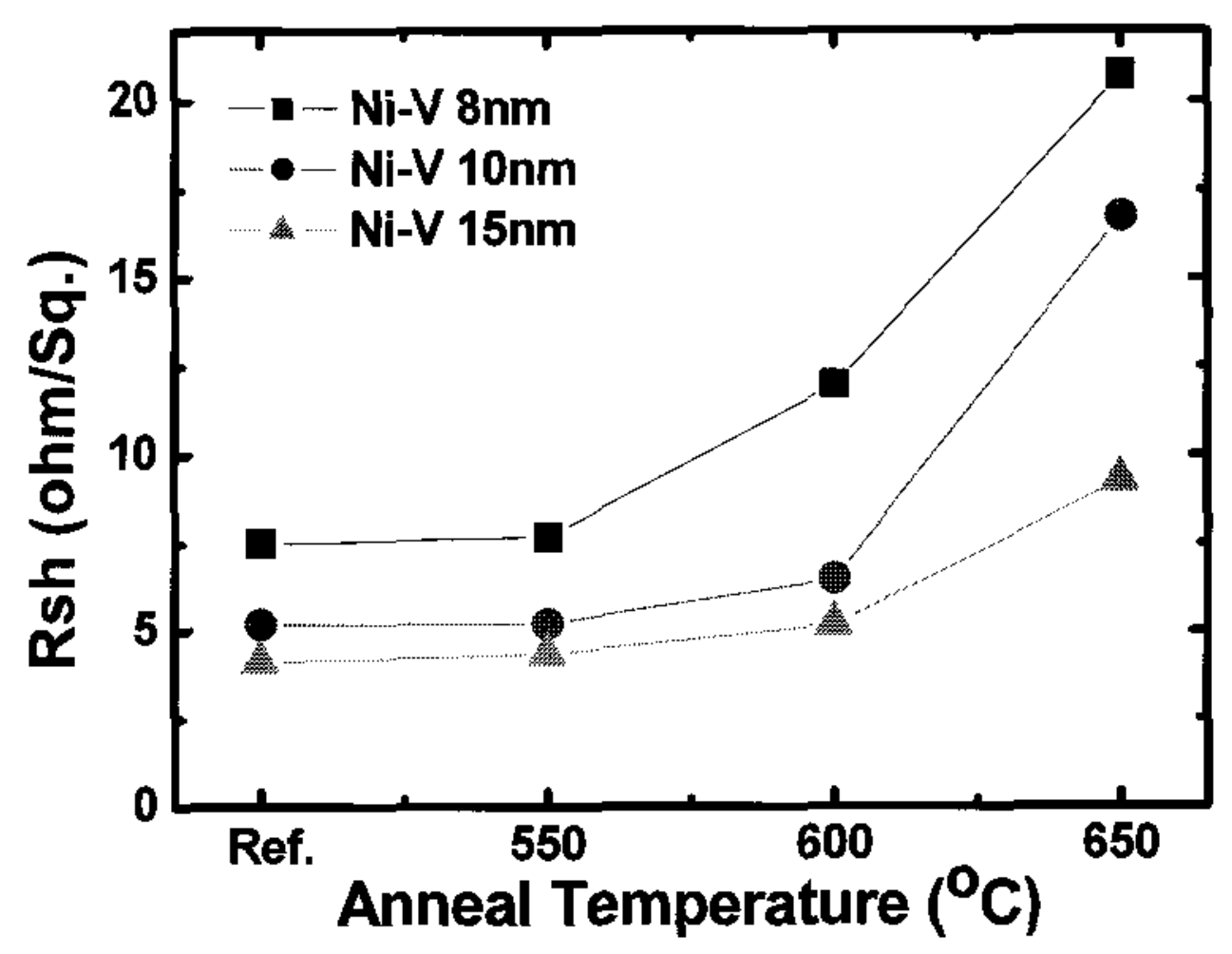

(b)

Fig. 7. Dependence of sheet resistance and thermal stability of Nickel silicide on the thickness of Ni-V (a) after silicidation (RTP) and (b) after post-silicidation annealing.

\section{ACKNOWLEDGMENTS}

This work was supported by grant No. (R01-2003000-11659-0) from the Basic Research Program of the Korea Science and Engineering Foundation (KOSEF).

\section{REFERENCES}

[1] Zhang S. L. and Ostling M., "Metal silicides in CMOS technology : Past, present and future trends", Critical Reviews in Solid State and Materials Sciences, Vol. 28, No. 1, p. 1, 2004. 
[2] T. Morimoto, T. Ohguro, H. S. Momose, T. Iinuma, I. Kunishima, K. Suguro, I. Katakabe, H. Nakajima, M. Tsuchiaki, M. Ono, Y. Katsuma, and H. Iwai, "Self-aligned nickel-mono-silicide technology for high-speed deepsubmicrometer logic CMOS ULSI", IEEE Transaction On Electron Devices, Vol. 42, No. 5, p. $915,1995$.

[3] C. Y. Lin, W. J. Chen, C. H. Lai, A. Chin, and J. $\mathrm{Liu}$ "Formation of Ni germano-silicide on single crystalline $\mathrm{Si} / \mathrm{sub} 0.3 / \mathrm{Ge} / \mathrm{sub} 0.7 / \mathrm{Si}$ ", IEEE Electron Device Letters, Vol. 23, No. 8, p. 464, 2002.

[4] H. Iwai, T. Ohguro, and S. I. Ohmi, "NiSi salicide technology for scaled CMOS", Microelectron. Eng., Vol. 60, p. 157, 2002.

[5] Lauwers A., Streegen A., de Potter M., Lindsay R., Satta A., Bender H., and Maex K., "Materials aspects, electrical performance, and scalability of $\mathrm{Ni}$ silicide towards sub-0.13 um technologies", Journal of Vacuum Science \& Technology B, Vol. 19, No. 6, p. 2026, 2001.

[6] Iwai H., Ohguro T., and Ohmi S. I., "NiSi salicide technology for scaled CMOS", Microelectronic Engineering, Vol. 60, p. 157, 2002.
[7] C. J. Choi, S. A. Song, Y. W. Ok, and T. Y. Seong, "Nickel-silicidation process using hydrogen implantation", Electronics Letters, Vol. 40, No. 6, p. 391, 2004.

[8] M. C. Sun, M. J. Kim, J. H. Ku, K. J. Roh, C. S. Kim, S. P. Youn, S. W. Jung, S. Choi, N. I. Lee, H. K. Kang, and K. P. Suh, "Thermally robust Tadoped NiSALICIDE process promising for sub-50 nm CMOSFETs", 2003 Symposium on VLSI Technology Digest of Technical Papers, p. 81, 2003.

[9] P. S. Lee, D. Mangelinck, K. L. Pey, J. Ding, D. Z. Chi, T. Osipowicz, J. Y. Dai, and A. See, "Enhanced stability of $\mathrm{Ni}$ monosilicide on MOSFETs poly-Si gate stack", Microelectronic Engineering, Vol. 60, Issues 1-2, p. 171, 2002.

[10] J. G. Yun, S. Y. Oh, B. F. Huang, H. H. Ji, Y. G. Kim, S. H. Park, H. S. Lee, D. B. Kim, U. S. Kim, H. S. Cha, S. B. Hu, J. G. Lee, S. K. Baek, H. S. Hwang, and H. D. Lee, "Highly thermal robust NiSi for nanoscale MOSFETs utilizing a novel hydrogen plasma immersion ion implantation and Ni-Co-TIN tri-layer", IEEE Electron Device Letters, Vol. 26, No. 2, p. 90, 2005. 